Coelho, E.A. Refletindo sobre turismo de base comunitária em Unidades de Conservação através de uma perspectiva amazônica. Revista Brasileira de Ecoturismo, São Paulo, v.6, n.1, jan/abr-2013, pp.313-326.

\title{
Refletindo sobre turismo de base comunitária em Unidades de Conservação através de uma perspectiva amazônica
}

\author{
Pondering on community-based tourism in protected areas through an \\ Amazon perspective \\ Eduardo de Ávila Coelho
}

\section{RESUMO:}

As unidades de conservação (UCs) têm sua origem também atrelada ao turismo, quando estes espaços começaram a ser pensados para o uso de moradores das cidades. No Brasil, a beleza cênica preservada nesses locais é responsável por atrair grande número de visitantes, em sua maioria, advindos de áreas urbanas. Muitas UCs possuem moradores em suas áreas ou nas proximidades e alguns destes vêm se organizando para trabalhar com o turismo de forma a garantir a tomada de decisão sobre os processos e otimizar os benefícios provenientes da atividade. Este trabalho visa refletir sobre algumas possibilidades para o turismo de base comunitária (TBC) desenvolvido em unidades de conservação, através da visão dos moradores locais, que formam esta base comunitária. Para isso, foram observadas algumas experiências de TBC na Amazônia brasileira, umas já implementadas, outras ainda em processo de planejamento. Em especial são discutidos aspectos observados em trabaIhos nas Reservas de Desenvolvimento Sustentável Amanã e Mamirauá, além de trabalhos e experiências pontuais na Reserva Extrativista do rio Unini, no Parque Nacional do Jaú, todas as quatro no Estado do Amazonas, no rio Tapajós e na ilha de Marajó, ambas no Pará. Diversas questões referentes aos próprios conceitos (e às práticas) de conservação, sustentabilidade, economia ecológica, populações tradicionais, turismo de base comunitária, entre outros, compõem esta reflexão sobre TBC na Amazônia, trazendo perguntas que precisam de profunda discussão entre os atores envolvidos para que se possa chegar a maiores definições sobre o TBC em UCs na Amazônia, levando em consideração a perspectiva local.

PALAVRAS-CHAVES: Turismo de Base Comunitária; Amazônia; Amanã; Conservação. 
Refletindo sobre turismo de base comunitária em Unidades de Conservação através de uma perspectiva amazônica

\begin{abstract}
Protected areas have their origin also associated with tourism, when these places started to be considered for the use of urban populations. In Brazil, the preserved scenic beauty in these places is responsible for attracting great number of visitors, most of which, coming from urban areas. Many protected areas have people living inside or in the vicinities and some of them are getting involved to work with tourism in such way as to guarantee the decision making over the processes and optimizing the benefits derived from the activity. This work aim to discuss some possibilities for community based tourism (CBT), developed in protected areas, through the perspective of the local residents. For this, experiences of CBT were observed in the Brazilian Amazon, some of which already implemented, others in the process of planning. In particular are discussed aspects observed on researches in the Sustainable Development Reserves Amanã and Mamirauá, as well as other works in the Unini River Extractive Reserve and the Jaú National Park, all four in the Amazonas State, and in the Tapajós River and the Marajó Island, both on Pará State. Many questions referring to the concepts themselves (as well as the practices) of conservation, sustainability, ecological economy, traditional populations, community based tourism, among others, compound this discussion about the CBT in the Amazon, raising questions that demand deep debates among stakeholders to make possible to come to major definitions about CBT on protected areas, taking into consideration the local perspective.
\end{abstract}

KEY WORDS: Community Based Tourism; Amazon; Amanã; Conservation.

\title{
Introdução
}

A preocupação com o ambiente degradado vem gerando diversas mudanças na forma como o ser humano busca o desenvolvimento. Mas a história das relações entre sociedade e natureza é de substituição de um meio natural por um meio cada vez mais artificial (SANTOS, 1996). Em contraste com essa separação entre homem e natureza, "ao longo do século XVIII [...] o romantismo valorizou uma relação imediata, pessoal e afetiva com a natureza" (ARAÚJO, 2007, p. 26).

Gómez-Pompa e Kaus (2000, p. 125) relatam que o mundo ocidental nunca "se preocupou tanto como agora com as questões que dizem respeito às relações entre os seres humanos e o meio ambiente". Desde a década de 80 , sustentabilidade é a palavra de ordem, mas este parece ser um conceito inatingível, seja por uma generalização de seus propósitos, seja por falta de interesse real dos tomadores de decisão.

O processo de urbanização também contribui para transformação dos espaços naturais, visto que mais pessoas adquirem hábitos de consumo urbanos e o campo passa a ser dominado por grandes corporações. Monte-Mór (2006, p. 06) coloca que a periferia da cidade se estende sobre seu entorno sob a forma de tecido urbano e, "cada vez mais as fronteiras entre o espaço urbano e o espaço rural são difusas e de difícil identificação". Milton Santos (2000, p. 92), ao examinar a modernização agrícola brasileira, diz que "o campo modernizado se tornou praticamente mais aberto à expansão das formas atuais de capitalismo que as cidades. Desse modo, [...] as áreas agrícolas se transformam agora no lugar da vulnerabilidade". Nas últimas décadas, a Amazônia parece ser a fronteira a ser conquistada por interesses pri- 
vados e pelos grandes projetos de desenvolvimento.

Em resposta aos problemas ambientais ocasionados pelo modo de vida das sociedades modernas surge a preocupação em proteger áreas naturais contra o processo de devastação, representada pela criação de áreas protegidas. Para Couto et al. (2004, p. 12), "a criação de unidades de conservação corresponde à estratégia básica para a promoção da proteção da diversidade biológica".

Na era moderna, os Estados Unidos foram o primeiro país a criar uma área protegida, em 1872, o Parque Nacional de Yellowstone (NPS, 2006). Vallejo (2003, p. 87) argumenta que "a criação de Yellowstone e de outros parques mundo afora, caracteriza também o início de uma fase em que o estado passa a ser o maior responsável pelo processo de implantação e gestão territorial das unidades de conservação, visando o benefício público".

O turismo já aparecia como um dos motivadores para a criação das áreas protegidas. Araújo (2007) relata que o início da criação dos parques americanos foi ainda motivado por interesses econômicos de empresários do ramo de transportes que visavam aproveitar o potencial turístico das áreas naturais. No Brasil foi criada a primeira UC da categoria, entre os estados de Minas Gerais e do Rio de Janeiro: o Parque Nacional do Itatiaia, estabelecido em 1937, nos moldes dos parques norte-americanos (SERRANO, 1997; SANSOLO, 2002). "Seu objetivo era incentivar a pesquisa científica, oferecer lazer às populações urbanas e proteger a natureza" (ARAÚJO, 2007, p. 68).

Pela lei do SNUC (Brasil, 2000) o Parque Nacional não permite áreas particulares em seu domínio, tendo o objetivo básico de preservação de ecossistemas naturais de relevância ecológica e beleza cênica, possibilitando atividades de educação e interpretação ambiental, a recreação em contato com a natureza e o turismo ecológico.

O estabelecimento de áreas protegidas parece ser uma alternativa necessária para que seja conquistada a preservação, no entanto, a criação de unidades de conservação não representa a resolução dos problemas ambientais e socioeconômicos locais, ao contrário, surgem novos e complexos desafios (COELHO, 2009).

Enquanto os parques valorizam o uso turístico, mas não permitem populações humanas em suas áreas, outras categorias de UCs permitem tanto a permanência das populações locais, como o turismo. Em alguns desses locais no Brasil, vem se expandindo o turismo de base comunitária.

O Turismo de Base Comunitária (TBC) é uma forma de as populações se apropriarem dos processos de decisão e controle e não deve ser reduzido a uma análise que considere apenas os benefícios econômicos como metas a serem alcançadas. Almeida et al, (2009, p. 69) colocam ser preciso considerar todo o potencial de desenvolvimento do turismo, "que supera a visão pautada unicamente em seus benefícios econômicos, para privilegiar novas abordagens, capazes de privilegiar o potencial humano e relacional inerente à prática do turismo de base comunitária". Mais do que um negócio, o turismo é feito de encontros, experiências e trocas, que são ricas para visitantes e anfitriões.

Segundo Irving (2009) o TBC tende a favorecer a coesão e o laço social e o sentido coletivo de vida em sociedade, promovendo a qualidade de vida, o sentido de inclusão, a valorização da cultura local e o sentimento de pertencimento, representando a interpretação "local" do turismo. Sansolo e Bursztyn (2009, p. 158) acreditam que o TBC deve ser visto "como a possibilidade de um novo paradigma para o turismo, cujas bases se assentam nas relações de hospitalidade, da vontade de receber para intercambiar o que se tem de mais ca- 
ro, que é o sítio simbólico de pertencimento". É nesta lógica de encontros, vivências, hospitalidade e trocas entre visitantes e anfitriões que se dá a essência do TBC. Estes Estes elementos essências podem ser anteriores à logica de mercado e acontecerem independentes dela, ou também se apropriarem de mecanismos de mercado, sem se tornar dependentes dele.

A Pan-Amazônia apresenta diversos exemplos de comunidades que vêm se organizando para trabalhar com o turismo. É o caso das Reservas de Desenvolvimento Sustentável Mamirauá (RDSM) e Amanã (RDSA), e Reserva Extrativista (ResEx) do Rio Unini no estado do Amazonas. Enquanto a primeira já desenvolve um projeto de turismo comunitário desde 1998, quando se iniciou a implantação da Pousada Uacari, as outras duas UCs estão se organizando para levantar as possibilidades para o TBC, as formas de organização locais, os possíveis impactos da atividade e sua viabilidade. No Pará, o Projeto Saúde e Alegria (PSA) trabalha com TBC na Floresta Nacional do Tapajós e na ResEx Tapajós-Arapiuns enquanto na ilha do Marajó, a Vila do Pesqueiro, se organiza para o TBC na ResEx Marinha de Soure (Figuras 1 e 2).

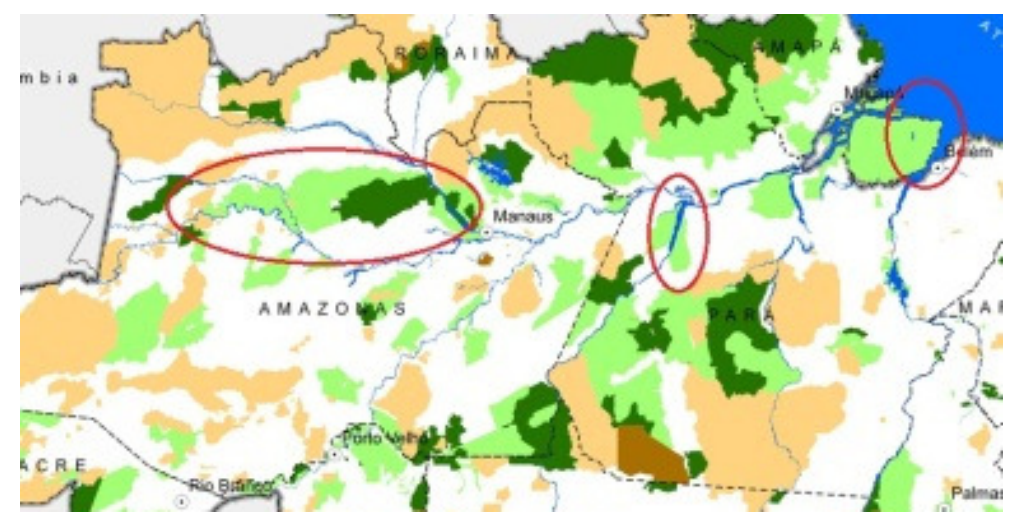

Figura 1: Corredor da Amazônia Central, rio Tapajós e llha de Marajó.

Figure 1: Central Corridor Amazon, Tapajos River and Marajó Island.

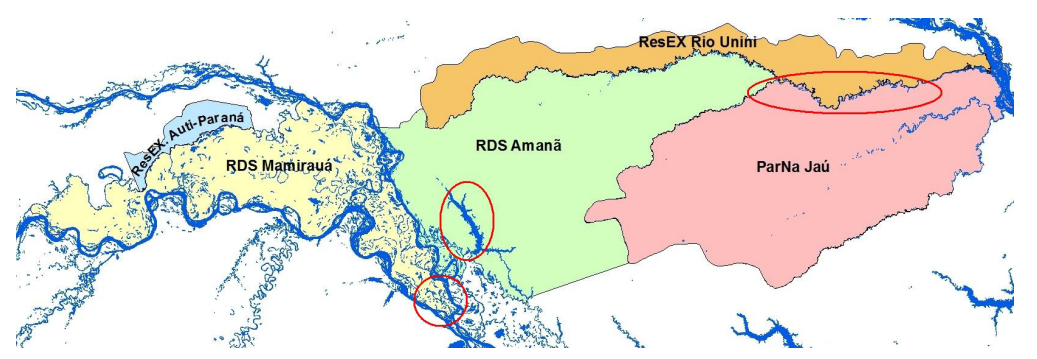

Figura 2: Detalhes da RDS Mamirauá (Pousada Uacari), RDS Amanã (Lago Amanã), e Rio Unini.

Figure 2: Details of RDS Mamirauá (Uacari Lodge), RDS Amanã (Lake Amanã), and Unini River.

\section{A Amazônia e o turismo de base comunitária}

A Amazônia é vista por grande parte dos brasileiros como uma região uniforme, tanto do ponto de vista natural, como cultural. Ao contrário, o que se vê é que a região que concentra a maior biodiversidade do planeta é, por isso mesmo, incrivelmente diversa em ambientes e populações humanas, que, ao longo da história, que remete a dezenas de milhares de anos, criaram diversas estratégias adaptativas que hoje refletem nesta sociobiodiversidade. 
Alencar (2007, p. 50), em seus estudos sobre a dinâmica territorial da Reserva Amanã, diz que a ocupação humana na região "reflete uma característica do processo mais amplo de ocupação da Amazônia promovida por uma economia centrada na exploração de recursos naturais". Este processo teve grande influência na forma de ocupação do espaço, enquanto o isolamento geográfico é apontado como um fator limitante à ocupação humana (ibidem).

Diante destas questões relacionadas à realidade das comunidades locais, que envolvem dependência da exploração de recursos, distanciamento geográfico, além de falta de atendimento adequado à saúde e a educação, faz-se necessária a abordagem de diversas variáveis envolvidas neste complexo contexto onde se inserem os processos de planejamento turístico.

Este trabalho pretende compreender melhor as possíveis implicações do turismo de base comunitária no contexto de unidades de conservação da Amazônia, partindo do ponto de vista das comunidades. As análises fazem parte da pesquisa de viabilidade do TBC na RDS Amanã (conduzida pelo Instituto de Desenvolvimento Sustentável Mamirauá - IDSM), onde se concentraram os trabalhos de campo entre 2009 e 2012. No período também aconteceram diversos trabalhos na vizinha RDS Mamirauá, além de duas expedições ao rio Unini e uma viagem ao Pará.

Como estratégia metodológica buscou-se o conhecimento da realidade local, principalmente através da observação participante, acompanhando as atividades diárias dos moradores, além da utilização de entrevistas semiestruturadas e reuniões com os principais grupos de atores e agentes envolvidos na dinâmica do TBC em UC.

Como afirmam Sampaio e Coriolano (2009, p. 08) "estudar comunidade faz-se necessário para compreensão desse segmento de turismo". Na Amazônia, as comunidades começaram a se formar em meados do século passado, em um movimento que partiu da igreja católica e estimulava a união dos moradores em um só local, para que tivessem mais força para lutar por seus direitos, entre saúde, educação e preservação do ambiente do qual ainda dependem.

A Amazônia também foi o berço de dois modelos de UCs de uso sustentável, onde as suas populações mantêm o direito de uso da terra: as reservas extrativistas e as reservas de desenvolvimento sustentável, ambas com importância histórica para o socioambientalismo. Como trata o art. 23 da lei do SNUC (BRASIL, 2000, p. 15), "a posse e o uso das áreas ocupadas pelas populações tradicionais nas reservas extrativistas e reservas de desenvolvimento sustentável serão regulados por contrato". Eles adquirem então uma concessão de direito real de uso. A mesma lei também dita que "as populações de que trata esse artigo obrigam-se a participar de preservação, recuperação, defesa e manutenção da unidade de conservação". É interessante perceber que, a lei que regulamente essas categorias de UCs ao mesmo tempo define as populações residentes como tradicionais e as obriga a se utilizar de práticas conservacionistas.

Carneiro da Cunha e Almeida (2009) falam sobre as populações tradicionais, enumerando seus "membros" ou candidatos a "membros" e apontam que, "termos como 'índio', 'indígena', 'tribal', 'nativo', 'aborígene' e 'negro' são todos criações da metrópole, são frutos do encontro colonial. E embora tenham sido genéricos e artificiais ao serem criados, esses termos foram progressivamente sendo habitados por gente de carne e osso".

São estas populações tradicionais, caboclas, ribeirinhas, seringueiros (ou exseringueiros), castanheiros, entre outros, que estão hoje agrupadas em comunidades no inte- 
Refletindo sobre turismo de base comunitária em Unidades de Conservação através de uma perspectiva amazônica

rior ou entorno das ResEx, RDSs e demais UCs da Amazônia e se organizam para trabalhar com o turismo de base comunitária.

Refletindo então sobre as possíveis formas de se trabalhar o turismo no meio rural na Amazônia, a primeira questão a se levar em conta é, como vivem essas populações? Lima (1992), em estudo sobre as comunidades da RDS Mamirauá, define essas populações como camponesas, pois, apesar de estarem articuladas ao mercado, apresentam autonomia relativa em relação a este. As economias camponesas são estruturadas no âmbito doméstico, em uma relação de produção e consumo para atender as necessidades do próprio grupo, geralmente, apenas o excedente é comercializado e a renda permite o acesso a bens industrializados.

Neste caso, o agroextrativismo de subsistência é a base da manutenção dos membros da família. Isto significa que muitas comunidades vivem basicamente da pesca e da caça para obtenção de proteína animal, da agricultura, que é muito diversificada e se destaca a mandioca para a produção da farinha amarela, da criação de pequenos animais e do extrativismo vegetal de itens como açaí, castanha, cipós, seringa e uma diversidade de outros. Respondendo à minha pergunta "o que vocês fazem aqui na comunidade", uma criança no rio Unini disse: "aqui a gente pesca peixe e faz farinha". Este relato resume de forma simbólica como é a vida no interior da Amazônia.

A frequência de relação com a cidade e o mercado, depende da distância entre as comunidades e os centros urbanos. O meio de transporte amazônico é, via de regra, fluvial, seja por canoa, antigamente a remo, hoje com motor rabeta, ou por barcos regionais. Estes meios de transporte são costumeiramente lentos e o tempo de deslocamento até a cidade mais próxima pode variar de poucas horas até alguns dias.

A organização sociopolítica através de comunidades permite o controle das decisões sobre diversos aspectos que compõe a vida cotidiana dos moradores. Desde a decisão sobre lagos a serem preservados, até reivindicações sobre saúde e educação perante aos governos locais e a organização entre as comunidades para trabalhar com o turismo.

A recente criação das unidades de conservação, transformando o lugar das comunidades em territórios legalmente protegidos, insere uma nova lógica de organização do espaço. Agora elas vivem em UCs onde atuam instituições governamentais e não-governamentais, muitas delas transnacionais. Entre diversos projetos conservacionistas que são levados por estas instituições, se inserem as propostas de TBC, que buscam atingir conservação levando melhoria de qualidade de vida para as populações.

Considerando este novo contexto (e seus desdobramentos e evoluções), é importante refletir sobre os conceitos que chegam a estas populações através de canais de comunicação, leis e agentes públicos e privados. O próprio conceito de conservação pode ter diferentes interpretações para quem o leva e para quem recebe. Segundo o SNUC (BRASIL, 2000) conservação da natureza é o manejo do uso humano da natureza, compreendendo a preservação, a manutenção, a utilização sustentável, a restauração e a recuperação do ambiente natural.

As pessoas que estudam, observam, legislam e impõem as práticas atribuídas ao conceito de conservação, analisam e julgam as práticas dos moradores locais, que também ganham conceitos como populações tradicionais, comunitários ou ribeirinhos. Ao julgarem estas ações, por vezes coíbem ou recriminam, por vezes são estas ações que influenciam a (re) formulação do próprio conceito de conservação. Enquanto os atores externos se apropriam do conceito, as populações locais se utilizam das práticas de conservação. Assim Diegues 
(2000, p. 41) ressalta que "os conservacionistas do Sul não tem outra escolha a não ser construir uma ciência e prática da conservação que surja das necessidades culturais e ambientais de seus países".

Da mesma forma podem ser pensados os conceitos atrelados a ecoturismo ou a turismo de base comunitária. Não tentando entender apenas como é feita a interpretação local dos conceitos, mas quais os elementos que compõem estes conceitos que podem ser encontrados nas práticas cotidianas, entre eles hospitalidade, reciprocidade, respeito ao outro, gratidão.

Estes elementos são independentes da economia de mercado, que, ao mesmo tempo também envolve o TBC. Mas para superar a lógica meramente econômica que muitas vezes se impõe ao turismo, pode se adotar a abordagem da economia ecológica. Alier (2007, p. 59) diz que "a economia ecológica difere da economia ortodoxa pela sua insistência em assinalar a incompatibilidade do crescimento econômico com a preservação em longo prazo dos recursos e dos serviços ambientais".

Ao se confrontar todos estes conceitos, há populações tradicionais com direito de uso sobre os territórios legalmente protegidos, utilizando-se de práticas tradicionais de manejo (e conservação) do ambiente, organizando-se para trabalhar com turismo, numa lógica que valoriza sua cosmovisão e não reduz a atividade ao mero crescimento econômico.

A Amazônia tem então a possibilidade de aproveitar a sua imensa riqueza cultural e natural. Becker (2002) estudando o caso de Silves, no Amazonas, expõe que muitos empreendimentos turísticos existentes se limitam à exploração do 'turismo da natureza', enquanto em Silves tenta-se criar uma intimidade, uma relação mais pessoal dos turistas com a população local e com a natureza. Este também parece ser o ponto crucial nas iniciativas de TBC aqui retratadas. Aubreton (2004) complemente que, a cada ano uma fração mais importante de turistas quer descobrir a Amazônia de uma maneira mais profunda, vivendo 'como um nativo'. Para a autora os turistas que buscam estas experiências procuram fazer das suas férias uma descoberta mais autêntica e desejam descobrir a realidade e o cotidiano dos habitantes da região, ficando também mais próximos da natureza.

Voltando a análise para as implicações do TBC na realidade dos moradores das UCs estudadas, algumas questões surgem para a discussão:

A organização do trabalho: como já mencionado, o grupo doméstico se organiza para as atividades que envolvem seu próprio sustento. Isso significa que a atividade mais ligada à obtenção de renda, seja ela pesca ou agricultura (dependendo da vocação do ambiente, ex. na várzea é a pesca e na terra firme a agricultura), é executada preferencialmente pelo homem. A mulher cuida da casa e da família (que costuma ser muito numerosa) e ainda ajuda o homem em diversas atividades ligadas ao sustento do grupo. As crianças também ajudam em atividades diárias, em que também se percebe uma divisão de gênero: as meninas ajudam a mãe a cuidar da casa e dos irmãos menores, enquanto os meninos vão atrás do peixe para consumo. Toda a família é envolvida na produção da farinha amarela, ao passo que caçar é uma atividade masculina.

Quando uma nova atividade se insere nesta realidade, inúmeras mudanças podem ocorrer. Peralta (2005) identificou uma redução na atividade agrícola nas comunidades da RDS Mamirauá que trabalham com turismo. A renda já é obtida pela prestação de serviços e, por vezes, até a farinha que era consumida pela família, precisava ser comprada. Isto tem ainda outras implicações visto que, na várzea, é o trabalho na terra que determina o direito à 
Refletindo sobre turismo de base comunitária em Unidades de Conservação através de uma perspectiva amazônica

sua posse. No entanto alguns moradores da RDS Amanã mencionaram que esperam que o turismo possa tirar as pessoas do trabalho pesado da roça.

Ao investigar o interesse dos moradores de Amanã em atuar no turismo, alguns diziam que não queriam trabalhar, pois não podiam deixar os seus afazeres diários para servir aos turistas, mas achavam que essa oportunidade de trabalho seria boa para seus filhos jovens. Outra questão importante, pois muitos jovens já não se interessam tanto em morar no interior, mas o turismo pode representar um trabalho que atrai estes jovens para continuar morando nas comunidades (ou retornar da cidade, quando vão buscar melhores condições de estudo). No entanto, como pode ser a participação no TBC, de jovens menores de idade? E como fazer para que a nova atividade não substitua as práticas tradicionais?

Dessa forma, as decisões sobre estratégias utilizadas para ter acesso a recursos devem recair sobre quem irá viver essas escolhas. Como afirmam Bursztyn et al (2009, p. 81) é importante "conceber modelos que busquem a superação das privações de liberdades que limitam as escolhas e as oportunidades das pessoas e comunidades que têm seus modos de vida situacionalmente afetados pela implantação dessas novas práticas".

Outra questão importante são as adaptações à realidade local para atender ao turista: os modos de vida na Amazônia envolvem uma relação intricada com a água e a floresta. As populações têm disponíveis praticamente todos os recursos que precisam para sua reprodução cultural, desde a madeira para construir casas, barcos e canoas, uma variedade de frutos e animais para a alimentação, áreas agricultáveis para produzir seu sustento, além de uma diversidade de estratégias de acesso ao mercado. Os recursos são acessados através do esforço e do trabalho e, no caso do turismo, os modos de vida se apresentam como a interlocução entre visitantes e o ambiente amazônico, sendo o principal 'atrativo' para os turistas. Sem a intermediação do nativo, é praticamente impossível para o visitante conhecer a Amazônia.

No entanto, dada a diferença entre estes modos de vida locais, daqueles trazidos pelos visitantes, muitas vezes a realidade local sofre modificações para atender aos de fora. Aspectos estruturais são alterados e atividades tradicionais são adaptadas para serem incluídas em roteiros turísticos. O jirau na beira, que é extensão da casa e local onde os moradores tomam banho na beira e desempenham outras atividades domésticas, é substituído por um banheiro, com chuveiro, água quente. Enquanto o morador vai ao igapó para colocar uma maIhadeira para pegar o peixe, o guia de turismo rema com seus clientes no mesmo igapó para avistar a fauna arborícola. Uma picada na mata se transforma em trilha de turismo e atividades de caça e retirada de castanha ou cipós, se transformam em passeio para ver bichos. A espingarda, fiel companheira na mata, é deixada para trás, para não causar aos visitantes o choque de ver um animal sendo caçado. Enquanto o boto é visto como ser encantado, causando até medo a alguns moradores, para o turista ele é um animal de grande interesse de avistamento e ele quer chegar cada vez mais perto (até alimentá-lo em muitos casos). Pouco a pouco a relação que os moradores têm com o lugar pode ser modificada devido às novas atividades que são executadas no ambiente. Mas ao serem feitas estas e outras adaptações, a vivência da realidade amazônica também não se altera?

Isto remete a outra questão importante para discussão: a caça. Os moradores dependem da caça para obtenção de alimento, principalmente nas áreas de terra firme. Quando a pesca é escassa recorrem aos animais da floresta, mas quando está muito farta também procuram caçar, pois 'enjoam' do peixe e querem carne. Diversos mamíferos, aves e répteis compõem a dieta ribeirinha. No entanto os moradores das cidades não tem esse hábito, então como seria considerado o consumo por eles?

Ao se pensar uma estrutura de pousada, a exemplo da Pousada Uacari em Mamirauá, 
parece óbvia a conclusão de que o consumo de carne de caça nestes locais não deve ser permitido. Mas e quando se trata de um turismo mais próximo das comunidades, com uso de hospedagem domiciliar e o acompanhamento do dia a dia dos moradores? A caça faz parte do cotidiano e muitas vezes esta carne pode ser o único alimento disponível nas comunidades. Pode ser então permitido o consumo pelos turistas? E quem decide são apenas os órgãos ambientais que impõem as leis que ditam sobre as práticas de conservação, ou os moradores também podem participar da decisão? Caso seja permitido esse consumo, isso irá aumentar a pressão sobre a fauna cinegética e comprometer os objetivos de conservação?

Os índios Katukina do rio Biá chegaram a uma resolução sobre a caça que pode servir para esta reflexão. Ao elaborarem o Plano de Gestão Territorial da Terra Indígena do rio Biá, apontaram as seguintes regras sobre a caça: "Katukina não pode deixar dyara (branco) caçar na terra. Dyara só pode comer carne de caça junto com Katukina na aldeia. Não podemos vender carne de caça para dyara" (Povo Indígena Katukina do Rio Biá, s.d., p. 17). Soluções deste tipo podem ser aplicadas em ResEx e RDSs? Se o turista que quer ficar na comunidade, e está pagando por isso, consome carne de caça, fica caracterizada a comercialização deste produto? O mesmo se aplica a peixes no período do defeso, como o pirarucu e o tambaqui, que não podem ser comercializados vários meses durante o ano, mas continuam sendo consumidos localmente. O turista pode consumir estes peixes?

Utilizando o aspecto da caça para refletir sobre a forma que moradores e forasteiros vêm o ambiente, enquanto um vê uma anta ou um bando de queixadas como segurança alimentar e fonte de proteína para vários dias e várias pessoas, o outro vê como um atrativo turístico. Mas eles se excluem? Ao levar um grupo de visitantes para caminhar no mato, o morador local pode levar sua espingarda caso encontre algum bicho (e até por segurança)? Os visitantes ficam chocados quando são expostos à realidade local, ou a admiram ainda mais? O seguinte relato é de um turista que visitou a Reserva Amanã em uma viagem experimental: "as atividades da caça e pesca para sustento próprio foi o que mais me chamou a atenção” (DANIEL, 2011).

No rio Unini, a pesca esportiva transformou a relação dos moradores com o tucunaré. Antes um peixe utilizado apenas para consumo, se transformou em fonte de renda através do turismo. Francisco, da comunidade Vila Nunes, relatou que chegou a receber 200 dólares de um turista por tê-lo levado a um local onde pescou um espécime com mais de 10 quilos. Até mesmo os apetrechos de pesca utilizados pelos moradores passam a incorporar elementos externos. Hoje em dia os moradores não pescam tucunarés grandes para preservá-los para os turistas.

No lago Amanã, um passaral de socó azul (Agamia agami) desperta interesse turístico e é tido como um local de alta atratividade, mas os moradores de uma comunidade fazem uso dos ovos durante os dois ou três meses em que as aves ficam agrupadas para terem os filhotes. Por estar a algumas horas de distância de canoa, essa coleta não é tão frequente, mas não há dados que permitam afirmar se o passaral irá manter-se ali. Estes exemplos demonstram como um recurso pode ter duas formas de aproveitamento distintas (direto e indireto), que podem ou não ser compatíveis.

Como último aspecto para reflexão, é interessante apontar outro caso do rio Unini. Afluente do rio Negro, o Unini tem sua bacia completamente protegida por três UCs. Na margem direita a RDS Amanã e o ParNa Jaú e na margem esquerda a ResEx do Unini, representando uma área contígua com mais de 5 milhões de hectares. São então duas UCs de uso sustentável criadas nos anos de 1998 e 2006 e uma UC de proteção integral criada em 1980. 
Ao longo do rio Unini dez comunidades se distribuem da seguinte forma: três na ResEx, seis no Parque Jaú e uma na RDS Amanã.

O Parque do Jaú, com mais de 2 milhões de hectares, não permite a permanência dos moradores, que há mais de 30 anos aguardam posicionamento do governo federal sobre a desapropriação. No rio Unini são aproximadamente 450 moradores na área do parque vivendo em situação 'ilegal'. Colchester (2000, p. 232) coloca ser uma verdade embaraçosa, somente agora admitida pelos conservacionistas, "que o estabelecimento da maioria dos parques nacionais e áreas protegidas teve consequências negativas sobre os habitantes locais". A questão segue indefinida e a mudança dos moradores de uma margem a outra, da área do parque para a área da ResEx não é tão simples quando pode parecer, visto que o Unini tem pouca terra firme próximo à calha do rio, sendo formado de imensa área alagável de igapó.

A Fundação Vitória Amazônica (FVA) trabalha um projeto de TBC no Unini e a situação dos moradores da área do Parque se torna mais uma vez um impasse: eles poderão participar do projeto e desenvolver turismo em suas áreas? A permanência destes moradores é incompatível com a conservação do Parque do Jaú? A lei do SNUC pode prever áreas de uso sustentável ocupadas por populações tradicionais antes da criação de uma UC de proteção integral? Grandes projetos turísticos que são desenvolvidos em parques nacionais (a exemplo do Parques da Copa, que acontece também no ParNa Jaú) são mais compatíveis com a conservação do que moradores que historicamente utilizam-se da área e podem desenvolver o TBC?

Existem, portanto, diversos formatos possíveis para as comunidades se organizarem para trabalhar com o turismo, em que variam os níveis de intervenção necessária para que os visitantes usufruam as experiências. Cada um implica em um investimento para iniciar a atividade, os custos operacionais, os esforços para gestão, bem como a demanda. Cabe aos moradores decidir qual caminho seguir, se apoiando em parceiros, visto que esta prática também demandará seu tempo e esforço.

\section{Conclusões}

Estas reflexões sobre turismo de base comunitária em unidades de conservação com populações tradicionais tiveram como intenção trazer questionamentos e não apontar definições, conclusões ou soluções.

Algo que parece claro em todos os casos estudados é que o envolvimento da população local com o turismo é lento, pois a nova atividade não faz parte da realidade local. As propostas de TBC costumam ser levadas por agentes externos e aos poucos os moradores incorporam o processo de tomada de decisão e empoderamento, no entanto o tempo de moradores e agentes externos (e seus projetos) costuma ser bem diferente. Muitas vezes são alguns poucos moradores que se interessam em liderar as atividades turísticas e com o tempo, outros vão aderindo.

Como principais questionamentos sobre a inserção desta nova atividade se destacam: a participação de jovens pode ser permitida a partir de qual idade, seguindo a lógica da organização familiar do trabalho? É mais importante fazer modificações e adaptações no ambiente e nos modos de vida, ou propiciar aos visitantes uma experiência genuinamente Amazônica, mesmo que esta seja muito distinta do que os visitantes estão habituados?

É possível permitir o consumo de carne de caça e de peixes no período do defeso pelos turistas, quando estes estão na casa dos moradores, ou deve-se organizar logística de 
abastecimento e armazenamento de frango e carne bovina para serem consumidos pelos visitantes? Muitas comunidades não têm acesso ininterrupto à energia elétrica, portanto, para armazenamento de produtos perecíveis, ou precisarão organizar uma frequência de abastecimento mais sistemática dos produtos, ou precisarão de muito gelo ou de muito combustível para funcionar os motores de luz para manter os freezers ligados. E qual destas opções é mais sustentável? Podem ainda conseguir, através de projetos, a instalação de tecnologias como a energia solar, como é o caso da Pousada Uacari.

Qual estilo de vida é mais favorável à conservação: o de um morador de uma área rural na Amazônia ou o de um morador de um grande centro urbano? Quando estes dois mundos se encontram, qual a influência cada um exerce sobre o outro e quais os reflexos destas influências para a conservação? Os relatos dos visitantes de Amanã mostram que a experiência representou algo valioso para eles: entender que não se precisa de tanto para ser realmente feliz. Este talvez seja o mais importante ensinamento para a atual sociedade de consumo, podendo ter implicações positivas para os processos de conservação.

O turismo pode ajudar a criar uma consciência conservacionista, quando os recursos passam a ter um valor de uso indireto, mas atrelar uma nova consciência conservacionista pelo ato de não utilização dos recursos para que estes passem a servir ao turismo, muda a relação que os moradores têm com aquele lugar.

E sobre o uso de embarcações: enquanto os moradores se utilizam de canoas e barcos regionais, que são lentos, mas permitem apreciar a paisagem, além de consumir menos combustível, os turistas são geralmente transportados em voadeiras e lanchas rápidas, que tem alto consumo de gasolina. Qual delas é mais apropriada para que visitantes conheçam de fato a Amazônia? Qual é mais propícia para o TBC?

Uma visitante de Amanã relatou sobre sua experiência: "achei interessante comparar a experiência da viagem no expresso com a volta de rabeta. $\mathrm{Na}$ ida, de barco fechado, rápido, barulhento e de grande porte, me senti mais isolada do ambiente e das pessoas que vivem na reserva. A volta de rabeta proporcionou maior proximidade com a flora e fauna e outros aspectos do meio ambiente, e também possibilitou maior interação com moradores e outras pessoas que encontramos no trajeto [...] eu sinceramente gostei mais do deslocamento de rabeta, apesar de ter demorado bem mais e de ter sido um tanto cansativo" (Anna, 2012).

Para finalizar, algumas reflexões de Hassan Zaoual expressam bem sobre a complexidade do contexto do TBC, considerando as realidades das UCs da Amazônia. "Fundamentalmente, é na diversidade que a nova demanda turística esgota suas motivações profundas. Em um mundo atormentado pela perda de referências, a necessidade de pertencimento, bem como de um intercâmbio intercultural, exprimem o desejo de uma procura de sentidos da parte dos atores" (Zaoual, 2009, p. 58-59).

\section{O autor ainda coloca que}

os atores locais dos sítios que constituem o objeto de um desenvolvimento turístico, procuram participar de sua economia sem, para tanto, abandonar o monopólio do processo sob pena de gerar os efeitos cruéis constatados nas experiências do turismo de massa: marginalização econômica e social dos atores locais, destruição cultural de sua identidade, esgotamento da qualidade ecológica dos sítios envolvidos etc. Há aqui uma convergência que interpela. Se olharmos de perto, trata-se do desejo de um diálogo de sentidos entre os visitantes e os visitados, que procura abrir um caminho através dos escombros que o turismo de massa uniformizador deixa para trás. Aqui, o reco- 
nhecimento intercultural faz sua irrupção e se rebela contra as forças do mercado que invadiram o universo das viagens e da aventura. Elas constituem um produto padrão e organizado. Resumindo, a economia padrão do turismo impede o diálogo das culturas e o reduz, no máximo, a um folclore. A indústria do turismo acaba assim, paradoxalmente, com o desejo da descoberta mútua que está, no entanto, na raiz do que motiva, realmente, os comportamentos dos atores presentes. À medida que esta intermediação constitui o objeto de uma comercialização, a autenticidade da relação de intercâmbio desaparece e dá lugar a uma ilusão, uma artificialidade que a demanda evita progressivamente. A viagem torna-se uma jaula e passa a impressão de que a mobilidade espacial é culturalmente imóvel, à medida que tudo é organizado de tal forma que o encontro com o outro aparenta um simulacro.

Para exemplificar o que o autor se refere, o relato de um visitante de Amanã demonstra a riqueza de uma experiência que pode ser considerada autêntica. Este visitante passou uma semana na Reserva, em uma viagem que foi planejada e executada por moradores das comunidades do lago Amanã. "É extremamente gratificante e enriquecedor conhecer uma região mágica como a Amazônia através dos olhos dos moradores: viver da maneira como eles vivem, comer do que eles comem (açaí natural colhido no dia, peixes frescos, frutas exóticas e a famosa farinha de mandioca) dormir em redes, jogar futebol nos campos enlameados, assistir novela na hora do funcionamento do exaustor de energia... É uma experiência fantástica que muda um pouco nossa concepção de vida e que nos ensina que não precisamos de muito para se viver" (Augusto, 30 anos).

Talvez seja este tipo de experiência transformadora, que buscam os turistas que procuram conhecer a base comunitária na Amazônia. $O$ desafio para facilitar estes encontros é grande, mas os resultados fazem o processo valer a pena para todos os envolvidos.

\section{Referências bibliográficas}

ALENCAR, E. Estudo da ocupação humana e mobilidade geográfica de comunidades rurais da Reserva de Desenvolvimento Sustentável Amanã - RDSA. Relatório Final. IDSM, 2007.

ALMEIDA, F. et al. Estudo do contexto sócio-ambiental de agricultores familiares do entorno do Parque Estadual do Ibitipoca - MG: a perspectiva do turismo como agente do desenvolvimento de comunidades rurais no entorno de áreas protegidas. Anais - II SIMBRAS, 2009.

ARAÚJO, M.A.R. Unidades de Conservação no Brasil: da república à gestão de classe mundial. Belo Horizonte: Segrac, 2007.

AUBRETON, T. Turismo fluvial: um trunfo a explorar na Amazônia Brasileira. In. NELSON, S.P.; PEREIRA, E.M. (orgs). Ecoturismo: práticas para turismo sustentável. Manaus: Editora Vale / UniNorte, 2004.

BRASIL. Lei 9.985/2000 SNUC. Sistema Nacional de Unidades de Conservação. Brasília, 2000. 
BURSZTYN, I.; et al. Turismo para quem? Sobre caminhos de desenvolvimento e alternativas para o turismo no Brasil. In: BARTHOLO, R.; SANSOLO, D.G.; BURSZTYN, I. (Orgs.). Turismo de base comunitária: diversidade de olhares e experiências brasileiras /. - Rio de Janeiro: Letra e Imagem, 2009.

COELHO, E.A. As mudanças na nossa terra: impactos socioambientais associados a unidades de conservação - 0 caso de três parques mineiros. Dissertação de mestrado Centro Universitário UNA. Belo Horizonte, 2009

COLCHESTER, M. Resgatando a natureza: comunidades tradicionais e áreas protegidas. In: DIEGUES, A. C. (org.). Etnoconservação: Novos rumos para a proteção da natureza nos trópicos. Annablume Editora: São Paulo, 2000.

COUTO, R.G. et al. Atlas de conservação da natureza brasileira: unidades federais. Metalivros: São Paulo, 2004.

DIEGUES, A.C. Etnoconservação da natureza: Enfoques alternativos. In: DIEGUES, A. C. (org.). Etnoconservação: Novos rumos para a proteção da natureza nos trópicos. Annablume Editora: São Paulo, 2000.

GÓMEZ-POMPA, A.; KAUS, A. Domesticando o mito da natureza selvagem. In: DIEGUES, A. C. (org.). Etnoconservação: Novos rumos para a proteção da natureza nos trópicos. Annablume Editora: São Paulo, 2000.

MARTÍNEZ ALIER, J. O ecologismo dos pobres: conflitos ambientais e linguagens de valoração. São Paulo: Contexto, 2007.

MONTE-MÓR, R.L. O que é o urbano, no mundo contemporâneo. Belo Horizonte: UFMG/Cedeplar, 2006.

NPS (NATIONAL PARK SERVICE). Yellowstone National Park student packet. Wyoming, 2006.

PERALTA, N. Os ecoturistas estão chegando. Dissertação de mestrado. UFPA - Belém, 2005.

POVO INDÍGENA KATUKINA DO RIO BIÁ. Plano de Gestão Territorial:Terra Indígena do Rio Biá. Projeto Aldeias, s.d.

SAMPAIO, C.A.C.; CORIOLANO; L.N. Dialogando com experiências vivenciadas em Marraquech e América Latina para compreensão do turismo comunitário e solidário. Revista Brasileira de Pesquisa em Turismo. v. 3, n. 1, p. 4-24, abril 2009.

SANSOLO, D.G. Aproveitamento da biodiversidade para a sustentabilidade. In: IRVING, M.A.; AZEVEDO, J. (orgs.) Turismo: desafio da sustentabilidade. São Paulo: Futura, 2002.

SANSOLO, D., BURSTYN, I. Turismo de base comunitária: potencialidade no espaço rural brasileiro. In: BARTHOLO, R.; SANSOLO, D.G.; BURSZTYN, I. (Orgs.). Turismo de base comunitária: diversidade de olhares e experiências brasileiras /. - Rio de Janeiro: Letra e Imagem, 2009.

SANTOS, M. A Natureza do Espaço: Técnica e Tempo, Razão e Emoção. 4 ed. Editora da Universidade de São Paulo: São Paulo, 1996. 
SANTOS, M. Por uma outra Globalização. Editora Record: Rio de Janeiro, 2000.

SERRANO, C.M.T. A vida e os parques: proteção ambiental, turismo e conflitos de legitimidade em unidades de conservação. In: SERRANO, C.M.T.; BRUHNS, T. (orgs.). Viagens à Natureza: turismo, cultura e ambiente. 4를 ed. Campinas: Papirus, 1997.

VALLEJO, L.R. Unidades de Conservação: Uma Discussão Teórica à Luz dos Conceitos de Território e de Políticas Públicas. GEOgraphia (UFF), Rio de Janeiro, Ano 4, ํ‥ 8, 2003.

ZAOUAL, H. Do turismo de massa ao turismo situado: quais as transições? In: BARTHOLO, R.; SANSOLO, D.G.; BURSZTYN, I. (Orgs.). Turismo de base comunitária: diversidade de olhares e experiências brasileiras /. - Rio de Janeiro: Letra e Imagem, 2009.

\section{Agradecimentos}

A todos os moradores das Reservas Amanã e Mamirauá, pelos três anos de convivência e aprendizados. Aos moradores dos rios Unini e Tapajós e Ilha do Marajó pela receptividade. Ao Instituto Mamirauá pela oportunidade da pesquisa e apoio, ao CNPq pela bolsa e à Fapeam pelas bolsas Pibic.

Eduardo de Ávila Coelho: Instituto Terra de Preservação Ambiental, Rio de Janeiro, RJ, Brasil

Email: turismo.meioambiente@yahoo.com.br

Link para o currículo Lattes: http://lattes.cnpq.br/6699311143257092

Data de submissão: 28 de junho de 2012

Data de recebimento de correções: 04 de janeiro de 2013

Data do aceite: 04 de janeiro de 2013

Avaliado anonimamente 